\title{
Use of glass granules to produce effective gypsum composites
}

\author{
Victoria Petropavlovskaya ${ }^{1}$,Tatiana Novichenkova ${ }^{1,{ }^{*}}$, and Kirill Petropavlovskii ${ }^{2}$ \\ ${ }^{1}$ TSTU, Production of building materials and structures Department, 170026, Tver, Russia \\ ${ }^{2}$ MGSU,Binders and concretes Department, 129337,Moscow, Russia
}

\begin{abstract}
The possibility of using glass hollow microspheres in selfreinforced gypsum composites in the work is investigated. The need to use microspheres for gypsum products is dictated by modern high requirements for safety and environmental protection to construction sites and the building materials industry. The dispersion characteristics and grain composition of Russian production glass hollow microspheres, as well as the main component, a gypsum binder, were studied. It was established that all compositions contain particles of micro- and nanometer size. It is shown that glass microspheres provide the structure of a composite with a hardened matrix a low density while maintaining the necessary strength without the introduction of expensive and environmentally unsafe chemical additives.
\end{abstract}

\section{Introduction}

The development of environmental and environmental aspects of the building materials industry, green building technologies and health-saving building materials has made it possible to make a technical breakthrough in the application of gypsum binders and materials [1-4]. This is due to their compliance with all modern requirements for the safety of production, use and disposal [2].

It is known that the goal of green construction is to reduce energy and material costs from the moment the design of the construction project to its demolition, including the stages of construction, operation and maintenance. At the same time, a high quality of life should be ensured, including a combination of comfortable living conditions with the usefulness and durability of construction projects.

Gypsum does not create a burden on the natural environment at all stages of the life cycle. When gypsum stone is dehydrated during the production of binders, only water vapor is released, which ensures high environmental friendliness of their production [1,2]. Energy costs for obtaining semi-aquatic gypsum are significantly lower than in the case of cement or other mineral binders, which meets the solution to the problem of energy conservation. In the case of the use of finished products based on gypsum, there is also no danger to people, animals and plants, which compares them favorably with modern synthetic materials [3]. It should also be noted that the modern development of materials science

${ }^{*}$ Corresponding author:tanovi.69@mail.ru 
allows the repeated recycling of gypsum, which until recently, in the 20th century, seemed impossible [3]. At the same time, issues of resource conservation and environmental protection are successfully resolved $[4,5,6]$.

However, today the requirements are increasing for the gypsum binders themselves from the standpoint of their manufacturability, workability and other indicators $[3,4,5]$. Since gypsum materials are most in demand to create a favorable indoor environment with high architectural expressiveness, the weight of the products obtained on the basis of gypsum binders is an important property among the requirements for finishing materials and structures. The combination of high strength and low density of materials can allow creating a new generation of building materials $[3,7,8]$.

In order to reduce the weight of gypsum products, various methods are used, such as the plastering of gypsum stone through the use of gas and foaming agents of various nature, the introduction of various porous natural and man-made lightweight fillers, as well as by using a synergistic effect when combining the first and second method $[6,8,9,10-12]$.

The average density of mortars using perlite and vermiculite in the form of expanded sand is reduced to $1140 \mathrm{~kg} / \mathrm{m}^{3}$. However, the introduction of hollow glass microspheres (PSMS) has more effective indicators (tens of times) for equally dense mixtures for all the studied properties: ultimate compressive strength, ultimate flexural strength, rheological properties of finished mixtures, etc. For example, the plastic strength of building mixtures with hollow microspheres is $4 \ldots 8$ times higher than the density for compositions with added perlite or vermiculite, which affects the technological properties of solutions. Mixtures with hollow microspheres retain vitality longer. They have a water retention capacity of $90 \%$ more. In this case, the mixtures do not lose their shape in the period before crystallization and have high adhesion to the base after it [7].

The introduction of $10 \%$ hollow microspheres of the MSO - "0" grade of class B1 of Novgorod production (TU-6-11-156-79) (Fig. 1) into the structure of high-strength gypsum stone makes it possible to obtain materials with a compressive strength of $3.4 \mathrm{MPa}$ and a strength at a bend of $1.78 \mathrm{MPa}$ at the age of 2 hours and an average density in the dry state of $868 \mathrm{~kg} / \mathrm{m}^{3}$. Moreover, the authors note a change in the structure of gypsum stone, which is confirmed by a decrease in the interplanar spacing in dihydrate crystals compared to pure gypsum [8].

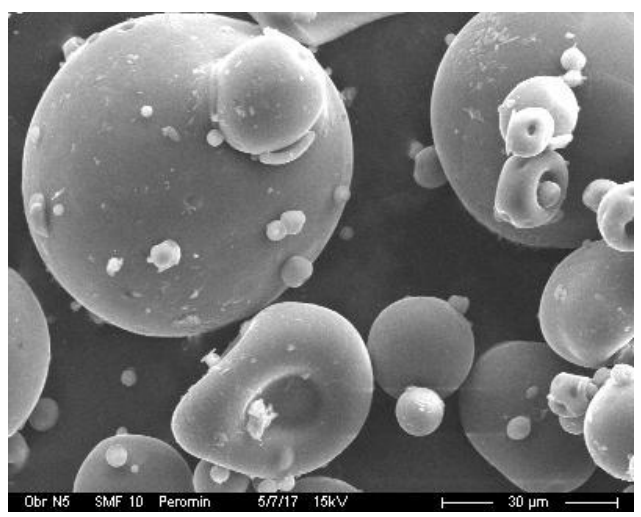

Fig. 1.Hollow microspheres MSO - «0» of the Novgorod production.

An important factor in the use of micro fillers is the dispersion of grains [15 - 17]. This is noted by many manufacturers [15]. Domestic production of glass hollow microspheres is significantly superior to foreign analogues in a number of indicators, primarily in terms of 
strength / density, therefore, in this study, to obtain an effective gypsum composite, we used material from Russian local microspheres.

\section{Experimental}

Studies to evaluate the effect of the addition of glass micro granules on the properties of a self-reinforced composite were carried out on the basis of a low-grade gypsum binder - G-5 BII gypsum production in the Moscow region. The main properties are listed below in table 1. The properties that are interesting for this study are indicated. First of all, this is the degree of grinding, bulk density and strength.

In this study, the GR microspheres of the Tver Plant were used as filler. Three compositions were studied in the work; the characteristics of their size distributions are shown in Fig. 3-5. Grain formulations are indicated additionally in tables 2 - 7. The best characteristics in the study according to the criterion of ratio and strength were shown by the composition of GR -2, therefore, these results are given in the work - the dependence of strength and density on the content of the additive of glass microspheres GR-2.

It was found that the average diameter of the microspheres in the GR-2 mixture is 16 $\mu \mathrm{m}$, the distribution mode corresponds to a grain size of $19.73 \mu \mathrm{m}$, and the distribution amplitude is: $(\mathrm{d} 90-\mathrm{d} 10) / 50=1.75$.

Table1.GypsumG-5 BII. Properties.

\begin{tabular}{|c|c|}
\hline Name of indicator & Value \\
\hline $\begin{array}{c}\text { Degree of grinding, the residue on a sieve } \\
\text { with a mesh size of } 0.2 \mathrm{~mm}, \% \text {, not more than }\end{array}$ & 14 \\
\hline Bulkdensity, $\mathrm{kg} / \mathrm{m}^{3}$ & $750-850$ \\
\hline $\begin{array}{c}\text { The tensile strength of beam samples at the age } \\
\text { of } 2 \text { hours, MPa, not less than } \\
\text { compressivestrength: } \\
\text { bendingstrength }\end{array}$ & 5 \\
\hline
\end{tabular}

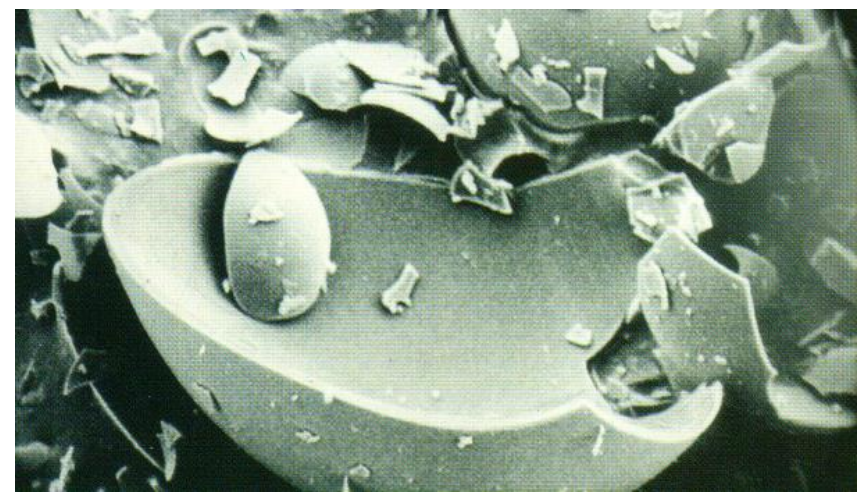

Fig. 2. Hollow microspheres GR-3of the Tver production.

As shown in fig. 4, the composition of GR-2 has the largest distribution in a narrow range from 5 to $30 \mu \mathrm{m}$ with a small grain content in the range from $0.1 \mu \mathrm{m}$ to $5 \mu \mathrm{m}$ and from $30 \mu \mathrm{m}$ to $50 \mu \mathrm{m}$. Other compositions - GR-1 and GR-3 have a smaller number of particles in this range, which, apparently, is reflected in the general particle size distribution of the raw material mixture with a gypsum binder. 


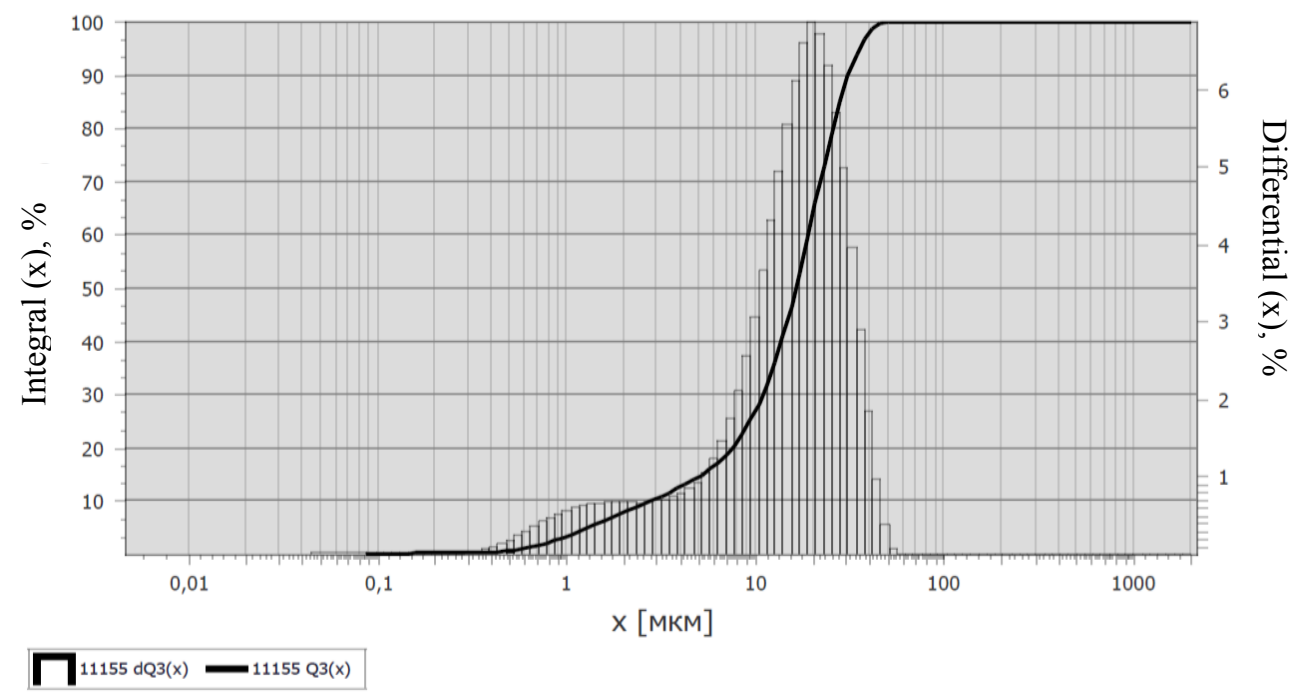

Fig. 3.Integral and differential distribution of glass microspheres GR-1 particles in the mixture.

The composition of the GR-1 mode is slightly higher: $21 \mu \mathrm{m}$ and the average particle diameter is $17.1 \mu \mathrm{m}$. The smallest average diameter corresponds to the composition of GR3. It is $14.7 \mu \mathrm{m}$. The particle distribution mode in the composition of the GR-3 mixture also corresponds to the smaller most probable particle size $-18.49 \mu \mathrm{m}$.

Table 2.Grain composition of glass microspheres GR-1.

\begin{tabular}{|c|c|}
\hline $\mathrm{d}(\mathrm{mkm})$ & $\mathrm{Q} 3(\mathrm{~d}), \%$ \\
\hline 0.1 & 0.07 \\
\hline 0.5 & 0.59 \\
\hline 1 & 3.22 \\
\hline 5 & 14.46 \\
\hline 10 & 26.78 \\
\hline 15 & 44.61 \\
\hline 20 & 63.02 \\
\hline 25 & 77.9 \\
\hline 30 & 88.01 \\
\hline 35 & 94.35 \\
\hline 40 & 97.68 \\
\hline 50 & 99.84 \\
\hline
\end{tabular}

Table 3.The weight distribution of glass microspheres GR-1 particles in the mixture.

\begin{tabular}{|c|c|}
\hline Q3(d), \% & $\mathrm{d}(\mathrm{mkm})$ \\
\hline 10 & 2.81 \\
\hline 50 & 16.43 \\
\hline 90 & 31.2 \\
\hline
\end{tabular}




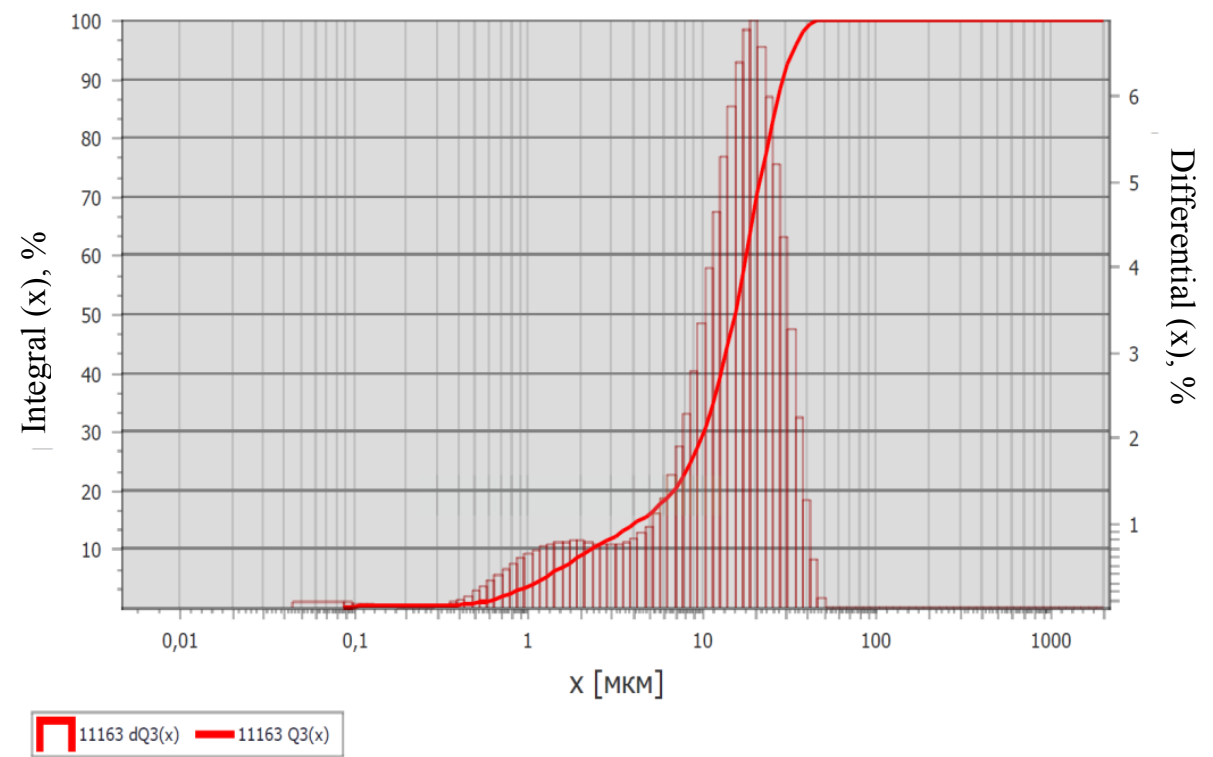

Figure 4.Integral and differential distribution of glass microspheres GR-2 particles in the mixture.

All integral particle distributions in the composition of all mixtures are quite "steep", the distribution shape characteristic, which is called the "shape factor", according to the calculation for the composition of GR-2 is $\sim 1.77$, for the composition of GR-1 $\sim 1.74$, and for the composition of GR -3 this characteristic is an intermediate value of $\sim 1.75$. Systems have a monomodal distribution (fig. 4, 5,6).

At the same time, gypsum binder is characterized by a large indicator on the characteristic of the distribution form - 3.21. This determines the flatness of the integral distribution curve. Thus, a mixture of gypsum binder with the addition of microspheres has a bimodal distribution of particles, which will affect the packaging of particles in the structure of the composite.

Table 4.Grain composition of glass microspheres GR-2.

\begin{tabular}{|c|c|}
\hline $\mathrm{d}(\mathrm{mkm})$ & $\mathrm{Q} 3(\mathrm{~d}), \%$ \\
\hline 0.1 & 0.14 \\
\hline 0.5 & 0.75 \\
\hline 1 & 3.61 \\
\hline 5 & 16 \\
\hline 10 & 29.16 \\
\hline 15 & 48.34 \\
\hline 20 & 67.32 \\
\hline 25 & 81.79 \\
\hline 30 & 90.95 \\
\hline 35 & 96.23 \\
\hline 40 & 98.71 \\
\hline 50 & 99.97 \\
\hline
\end{tabular}


Table 5.The weight distribution of glass microspheres GR-2 particles in the mixture.

\begin{tabular}{|c|c|}
\hline Q3(d), \% & $\mathrm{d}(\mathrm{mkm})$ \\
\hline 10 & 2.35 \\
\hline 50 & 15.42 \\
\hline 90 & 29.36 \\
\hline
\end{tabular}

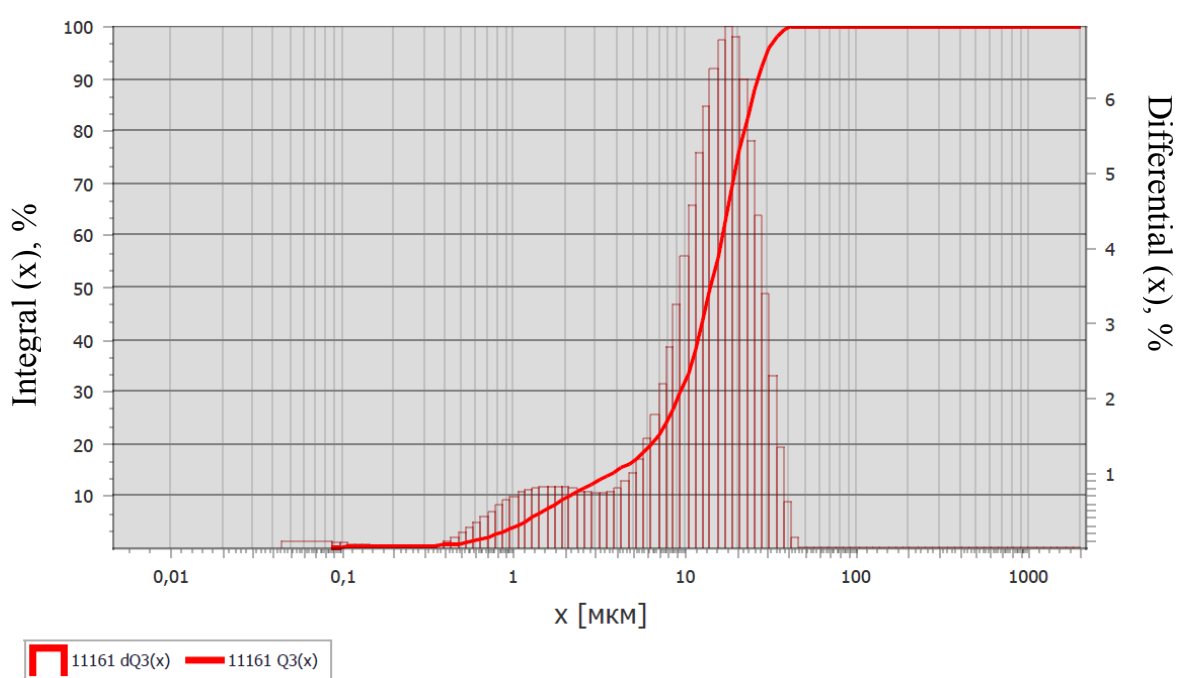

Fig. 5.Integral and differential distribution of glass microspheres GR-3 particles in the mixture.

The test results for the strength and density of the self-reinforced composite are shown in fig. 6, 7. It is shown that the water-solid ratio has little effect on the average density of the composite. This is due to the shape and surface quality of the granules. Micro granules not only increase water demand, but also increase the workability ofthe whole mixture. The effect of W/S is manifested for a mixture without filler or with a small amount.

However, the water-solid ratio affects the strength of the composite. Increased W/T reduces strength. For W/S $=0.6$ and W/S $=0.62$, the curves are closer in character. The lowest density corresponds to the content of microspheres $-30 \%$ and amounts to $858 \mathrm{~kg} / \mathrm{m}^{3}$.

The optimal composition of the mixture according to the criteria of strength and density is characterized by a granule content of $30 \%$ atW/S $=0.6$.

Table 6. Grain composition of glass microspheres GR-3.

\begin{tabular}{|c|c|}
\hline $\mathrm{d}(\mathrm{mkm})$ & $\mathrm{Q} 3(\mathrm{~d}), \%$ \\
\hline 0.1 & 0.17 \\
\hline 0.5 & 0.84 \\
\hline 1 & 3.91 \\
\hline 5 & 16.7 \\
\hline 10 & 31.83 \\
\hline 15 & 53.36 \\
\hline 20 & 73.01 \\
\hline 25 & 86.66 \\
\hline 30 & 94.33 \\
\hline 35 & 38.14 \\
\hline 40 & 99.56 \\
\hline 50 & 100 \\
\hline
\end{tabular}


Table 7.The weight distribution of glass microspheres GR-1 particles in the mixture.

\begin{tabular}{|c|c|}
\hline $\mathrm{Q} 3(\mathrm{~d}), \%$ & $\mathrm{~d}(\mathrm{mkm})$ \\
\hline 10 & 2.14 \\
\hline 50 & 14.23 \\
\hline 90 & 26.83 \\
\hline
\end{tabular}

Table 8.The weight distribution of gypsum.

\begin{tabular}{|c|c|}
\hline Q3(d), $\%$ & $\mathrm{~d}(\mathrm{mkm})$ \\
\hline 10 & 0.71 \\
\hline 20 & 1.4 \\
\hline 30 & 2.27 \\
\hline 40 & 3.25 \\
\hline 50 & 4.5 \\
\hline 60 & 6.24 \\
\hline 70 & 8.67 \\
\hline 80 & 11.71 \\
\hline 90 & 15.65 \\
\hline
\end{tabular}

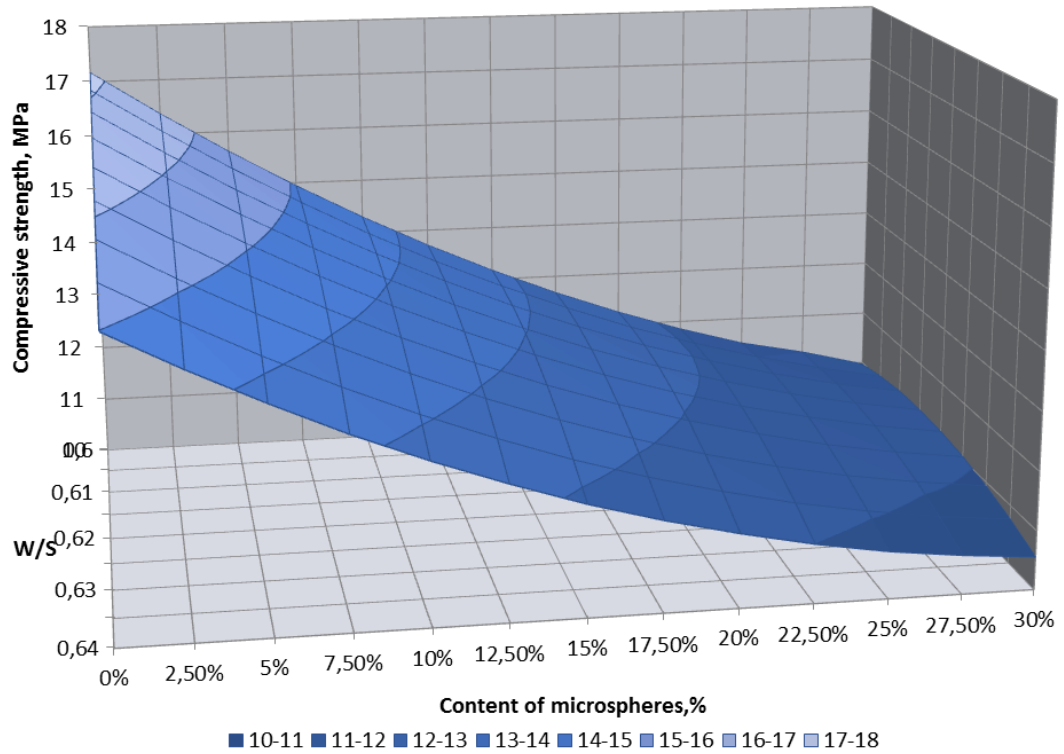

Fig. 6.The effect of the addition of microspheres on the strength of the gypsum self-reinforced composite at various $\mathrm{W} / \mathrm{T}$.

The gypsum self-reinforced composite with the addition of GR micro granules has an average strength of $\sim 11 \mathrm{MPa}$ at a density of $858 \mathrm{~kg} / \mathrm{m}^{3}$. Without adding expensive chemical modifiers. 


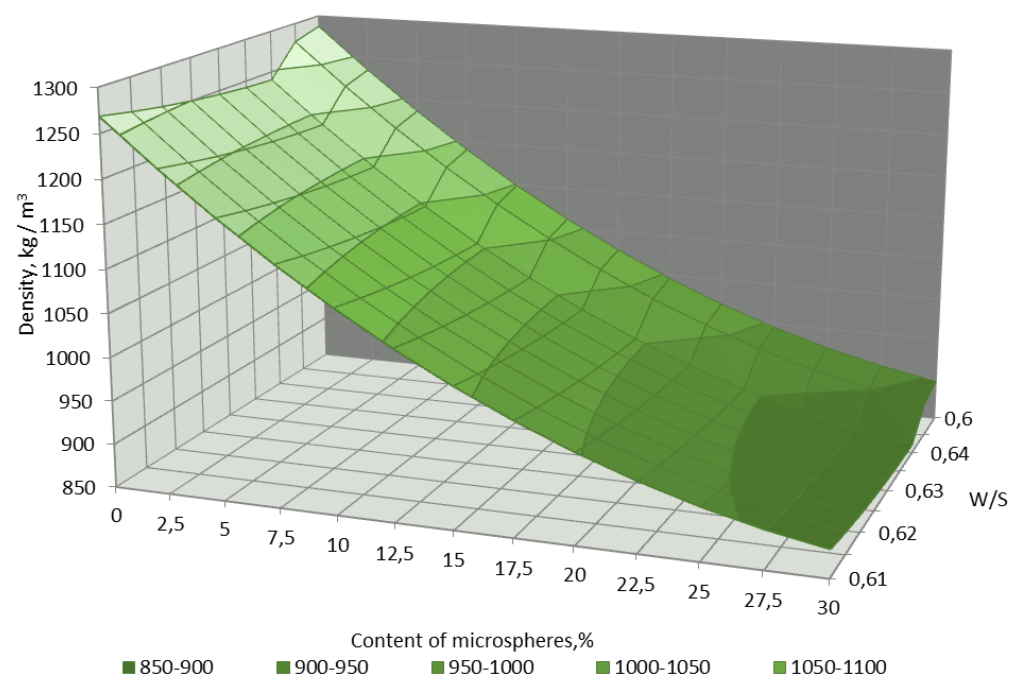

Fig. 7.The effect of the addition of microspheres on the density of the gypsum self-reinforced composite at various $\mathrm{W} / \mathrm{T}$.

Thus, the studies confirmed the possibility of obtaining a lightweight gypsum composite based on glass hollow microspheres. The introduction of glass micro filler allows you to use the material to create a wide range of $3 \mathrm{D}$ gypsum products. The granulometric and dispersed composition of the filler does not create technological difficulties for its similar implementation.

\section{References}

1. N.A. Sapelin, V.N. Khoglov,Suhiestroitel'nyesmesi. 5, 30-33 (2012)

2. N.A. Galtseva, Innovation and modelling in building materials science(2016)

3. N. Lushnikova, L. Dvorkin,Sustainability of construction materails.DOI: 10.1016/B978-0-08-100370-1.00025-1

4. V.B. Petropavlovskaya, A.F. Buryanov, T.B.Novichenkova, K.S. Petropavlovskii,The self-reinforced gypsum composites (De Nova, 2015)

5. V.Petropavlovskaya, A.Buryanov, T. Novichenkova, K. Petropavlovskii,IOP Conference Series: Materials Science and Engineering,365, 032060 (2018)

6. M.S. Lebedev,Tekhnicheskienauki - otteorii k praktike. 7-8 (44), 126 - 140 (2015)

7. K.I. Kirillov,Improvement of thermophysical properties of masonry solutions, Belgorod: BGTU im. V.G. SHuhova, 4,pp. 57 (2004)

8. T.E. Haev, E.V. Tkach, D.V. Oshchkin,Stroitel'nyematerialy, 10, 45-50 (2017)

9. A.A. Pashkevich, E.G. Pervushin, D.V. Oshchkin,Hollow glass microspheres and cement systems,M.: NIISF, 134-139 (2006)

10. J.M. Gomez-Soberon,F.G. Cabrera-Covarrubias, J.L. Almaral-Sanchez, M.C. GomezSoberon, Advances in Materials Science and Engineering (2018). Article ID 1386946. DOI:.org/10.1155/2018/1386946

11. Yu. Song, David A. Lange, Applied Sciences,9(5), 876(2019). DOI: 10.3390/app9050876

12. K.S. Petropavlovskii, A.F. Buryanov, V.B. Petropavlovskaya, T.B. Novichenkova, Stroitel'nyematerialy, 10, 40-45 (2019)

13. Y.-Sh. Wang, J. L. Provis, J.-G. Dai Role, Cement and Concrete Composites,93,186- 
$195(2018)$

14. V.S. Semenov, T.A. Rozovskaya, Stroitel'nyematerialy,6, 16-19 (2015)

15. V.F. Draper, Glass Ind.,v. 62,10,13-20 (1981)

16. V.B. Petropavlovskaya, T.B. Novichenkova, V.V. Belov, A.F. Buryanov,Stroitel'nyematerialy,1, 64-65 (2013)

17. V.B. Petropavlovskaya, T.B.Novichenkova, K.S. Petropavlovskii, A.F. Buryanov,Stroitel'nyematerialy, oborudovanie, tekhnologii XXI veka. 1 (192), 15-17 (2015)

18. V.V.Budov, L.S. Egorova, Glass and ceramics, 7, 2-5 (1993)

19. Ahmad Shayan, XuAimin, Cem. Concr. Res.,36 (3), 457-468 (2006)

20. N. Schwarz, H. Cam, N. Neithalath,Cem. Concr. Compos. 30 (6), 486-496 (2008) 